tion about the middle of the third millennium B.C. in and around the great steppe, which reached north China and may be responsible for some of the drifts to America.

So far as the steppes of western Asia and southern Russia are concerned, the broad-headed type was not the earliest in the population. The graves of the third millennium yield a majority of extreme long heads, differing from the hunter and collector people surviving farther south. This type spread into Europe from the early Bronze Age onwards. Later in the Bronze Age came a period of warmth and drought which leaves the steppe poor in remains and probably accounts for the small extent to which inter-tropical Africa was influenced by Bronze Age movements. The Bronze Age movements distributed skilled craftsmen with a high grade of organisation far and wide; while as regards the steppe the movements had acquired the driving power of the acquisition of the horse. Hence their movements were turned towards Iran and India, in directions in which conditions were suitable, rather than to the north-east. These peoples are generally credited with being the authors of the Aryan languages. Their relation to the people of the Old Stone Age is not clear.

There remains a long-headed element, or rather on the long-headed side of medium, found in western Europe, as for example in Britain and eastern Asia, notably in China. There are indications of a spread of early agriculturists through south-eastern Asia to north China, which included moderately long-headed elements as well as broad-heads; and this element may also have been included in a similar migration to western Europe, but lack of data precludes dating.

\section{Industry and the Research Associations}

$\mathrm{O}$ March 22, the Department of Scientific and Industrial Research convened an important conference at the Institution of Civil Engineers, at which Lord Rutherford presided, and more than one hundred representatives of the twenty-one research associations formed under the auspices of the Depart. ment were present. The object was to provide an opportunity for frank discussion with officers of the Department and nembers of its Advisory Council on the present position of the research association movement and its future.

On the eve of the conference, Sir Kenneth Lee, who is a member of the Advisory Council closely identified with the work of the research associations, and whose firm belief in industrial research is well known, entertained the representatives to dinner at the Dorchester Hotel. Mr. Runciman represented the Government and many prominent men in industry, finance and in the Civil Service were present. Among the speakers were Mr. Runciman, Lord Rutherford and the Right Hon. Reginald MeKenna. In the course of his remarks, Mr. Runciman read a statement from the Lord President of the Council, in which Mr. Baldwin said that those present no doubt shared the opinion of the Advisory Council that the present scale of operations of the research associations is totally inadequate if they are to serve their full purpose. He looked forward, with confidence, to industrialists improving matters in that respect, especially now that the prospects of trade are more promising. If they do so, Mr. Baldwin's message continued, they can rely on the Government on its side being prepared to play some part in the forward movement and to help in extending the scale of operations.

The views expressed at the conference left no doubt that the Advisory Council of the Department is right in believing that the time is ripe for a great development in the research association movement. The associations have already made a deep impression on British industry, not only in producing practical results of great monetary value, but also in bringing about a more sympathetic attitude towards the usefulness of scientifically trained men in the works. Several speakers emphasised the paramount duty of research associations of carrying out long-range investigations essential to widening the boundaries of knowledge. Reference was made to the benefits conferred on the consumer by the improvement in products as regards utility and price and to the raising of the standard of living resulting therefrom, and for this reason it was urged that a continuation of a substantial contribution from Government sources is fully justified. Attention was also directed to the importance of achieving stability of finance for the research associations as a means of securing the best work from those employed by them, of ensuring that the best scientific brains are available for that purpose and of making possible the planning of long-distance programmes.

At the conclusion of the proceedings, Lord Ruther. ford referred to the statement made by Mr. Runciman the previous night on behalf of the Lord President as to the willingness of the Government to afford increased financial help, and urged that as a next step the councils of the research associations should consider the scale of work required to meet the needs of their particular industries and submit proposals for the consideration of the Department, in order to bring about at the earliest possible date a very different scale of operations.

\section{University and Educational Intelligence}

CAMBridge.-The following appointments have been made: Dr. W. A. H. Rushton, of Pembroke College, to be University lecturer in physiology. Mr. O. A. Trowell, of St. John's College, to be University demonstrator in physiology and Dr. H. N. Green to be University demonstrator in pathology.

LEEDS.-The following appointments have recently been made : Dr. Douglas H. Collins, to be research fellow in rheumatism under the scheme of co-opera. tion between the University of Leeds and the Harrogate Royal Bath Hospital, for the institution of research into the cause and cure of chronic rheumatism and allied conditions; Dr. W. A. Bain, to be lecturer in physiology.

THe Educational Advisory Board of the British Social Hygiene Council is proposing to form a perma. nent central exhibit of biological teaching material and apparatus. In view of the increasing demand for including biology in school curricula, such an exhibit should prove useful to teachers. The Board is therefore seeking suggestions in connexion with all forms of biological material. Further information concerning the proposal and a list of suggested headings under which information is sought can be obtained from Mr. Percy F. Lee, Education Officer, Educational Advisory Board, British Social Hygiene Council, Carteret House, Carteret Street, London, S.W.1. 